\title{
Clinical Outcome in Patients with Early versus Delayed Decompression in Cervical Spine Trauma
}

\author{
Muhammad Sohail Umerani ${ }^{1}$, Asad Abbas ${ }^{1,2}$, Salman Sharif ${ }^{1}$ \\ ${ }^{1}$ Department of Neurosurgery, Liaquat National Hospital and Medical College, Karachi, Pakistan \\ ${ }^{2}$ Department of Surgery, Ziauddin University Hospital, Karachi, Pakistan
}

\begin{abstract}
Study Design: Prospective observational study.
Purpose: To assess the clinical outcome after early versus late decompression for traumatic cervical cord injury.

Overview of Literature: Traumatic spinal cord injury is common globally with the most tragic outcomes in the cervical spine. Although recent studies have shown that early decompression results in more favourable outcome, its authority is yet to be established. Methods: Study on 98 patients with a traumatic cervical cord injury was conducted over a period of 5 years. The patients who were operated on within 24 hours of the onset of the primary injury $(n=34)$ were classified as the early group, and those who were operated on after 24 hours of the onset of the injury $(n=64)$ were categorized as the late group. The outcome of both the groups was assessed using the American Spinal Injury Association (ASIA) Impairment Scale (AIS) at the 6-month follow-up.

Results: The patients in the early group were operated on at a mean time of 18.4 hours (range, 13-24 hours) while patients were operated on at a mean time of 52.7 hours (range, 31-124 hours) in the late group. At the 6-month follow-up, 7 (23.3\%) in the early group and $5(8.7 \%)$ in the late group showed $>2$ grade improvement in the AIS.

Conclusions: The results of patients undergoing decompression within 24 hours of the injury are better than those who are operated on later. An attempt should be made to decompress the traumatic cervical spine early in all possible cases.
\end{abstract}

Keywords: Spinal cord injuries; Spinal fractures; Surgical decompression; Spinal fixation; Treatment outcome

\section{Introduction}

Spinal cord injury (SCI) is estimated to affect over 750 million people worldwide [1]. It has an immense social and financial impact on society. This type of injury is much worse in the cervical region, which is involved in up to one-third of the cases [2]. These injuries may be complete, incomplete or may involve only the nerve roots. Much research is being done to counter the effects of SCI. These therapeutic measures are based on the pathophysiology of both the primary injury that is caused by the sudden compression of the spinal cord, and the secondary injury caused by the activation of cascades after the primary injury $[3,4]$. The use of steroids has been investigated by the National Acute Spinal Cord Injury Studies (NASCIS). There is a proposed modest benefit of methylprednisolone in SCI when it is given within 8 hours of the injury, with treatment initiated within 3 hours being better $[5,6]$. However, these results could not be validated because of a number of limitations [7].

Surgical intervention in cervical SCI is controversial; however, the timing of surgical intervention is under fur-

Received Aug 26, 2013; Revised Oct 11, 2013; Accepted Oct 11, 2013

Corresponding author: Asad Abbas

Department of Surgery, Ziauddin University Hospital, J-8 3rd floor, Yaqoob Terrace,

Main Gurumandir Round about, Karachi-74800, Pakistan

Tel: +92-333-3183523, Fax: +92-21-35862940, E-mail: asad.abbas@live.com 
ther debate. The dispute in timing is not limited to early or late decompression, but also extends to the definitions of early and late surgery as these definitions are also not uniform [8]. A number of animal and human studies have already been conducted for establishing the time frame of surgical intervention in SCI. The results have suggested a tendency towards early surgery. However, none of the randomized trials could be conducted on humans because of the obvious risk of delay in surgery.

\section{Materials and Methods}

The prospective non-randomized study was conducted from January 2007 to December 2011 at our tertiary care spinal trauma unit. This observational study was approved by the Ethical Review Committee of the institution. A total of 98 patients presenting with a cervical SCI undergoing decompressive surgery were recruited in the study. These were divided into two groups on the basis of the time interval from the trauma to the surgery. An effort was made to conduct the surgical procedure as soon as feasible; however, procedures were sometimes delayed due to a number of reasons including late presentation after the trauma, delay in consent or delay due to the medical condition of the patient. Patients who successfully underwent surgery within 24 hours of the injury were classified as the early group $(n=34)$, while those operated on after this period were included in the late group $(\mathrm{n}=64)$.

All patients presenting with a cervical cord injury from the C 3 to the T1 level and who were aged between 18 years and 65 years were considered. However, patients with a Glasgow Coma Scale of $<14$ or an American Spinal Injury Association (ASIA) Impairment Score (AIS) grade of $\mathrm{E}$ at presentation were excluded from the study. A detailed clinical examination assessing the severity of the injury including evaluation of the AIS, followed by an X-ray and magnetic resonance imaging of the cervical spine, was performed on admission (Fig. 1). Any associated injuries were managed accordingly.

Patients with X-ray evidence of locked facets were treated with Gardner-Wells Tongs with the appropriate weight for closed reduction till the surgical procedure and decompression could be performed (Figs. 2-4). The number of levels fused was individualized using an appropriate iliac bone graft. Fusion and fixation was done under fluoroscopic guidance. Postoperative X-rays of the cervical spine were taken for confirmation of the reduction and alignment, and to check the position of the im-

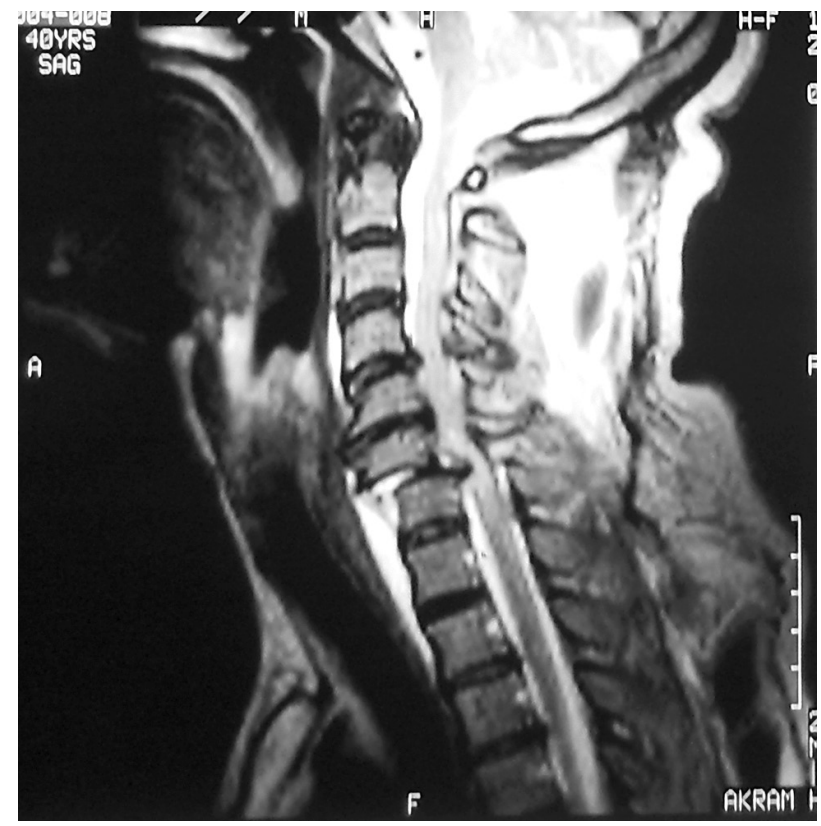

Fig. 1. Magnetic resonance imaging cervical spine T2-weighted image showing retropulsion of the $\mathrm{C} 7$ vertebral body with severe canal compromise along with signal changes in the cord. There is also a hyperintense signal of a haematoma in front of the body extending up to T2.

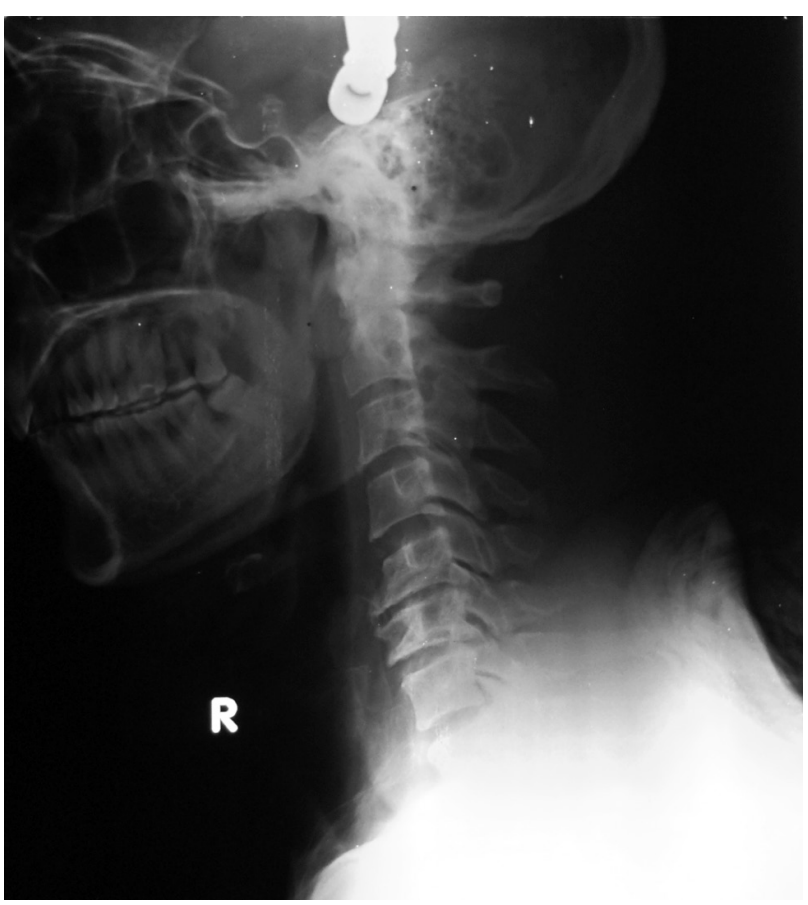

Fig. 2. X-ray cervical spine lateral view of the same patient showing the alignment of the cervical spine with reduction of the retropulsed $\mathrm{C} 7$ body after application of cervical tongs with adequate weights attached. 
plant (Fig. 5).

Extensive rehabilitation programs were tailored for each patient. Regular outpatient appointments were scheduled to evaluate the neurological status, especially the AIS at the end of the sixth postoperative month,

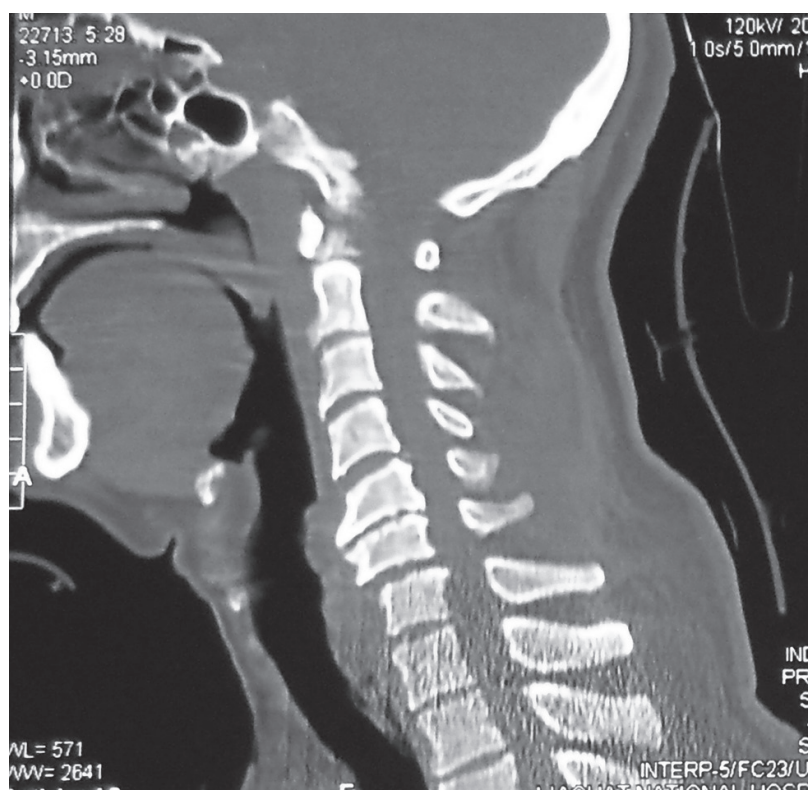

Fig. 3. Computed tomography scan cervical spine of the same patient performed after reduction. which remained as the primary outcome measure. The researcher collecting the data on the follow-up was blinded about the group to which a particular patient belonged.

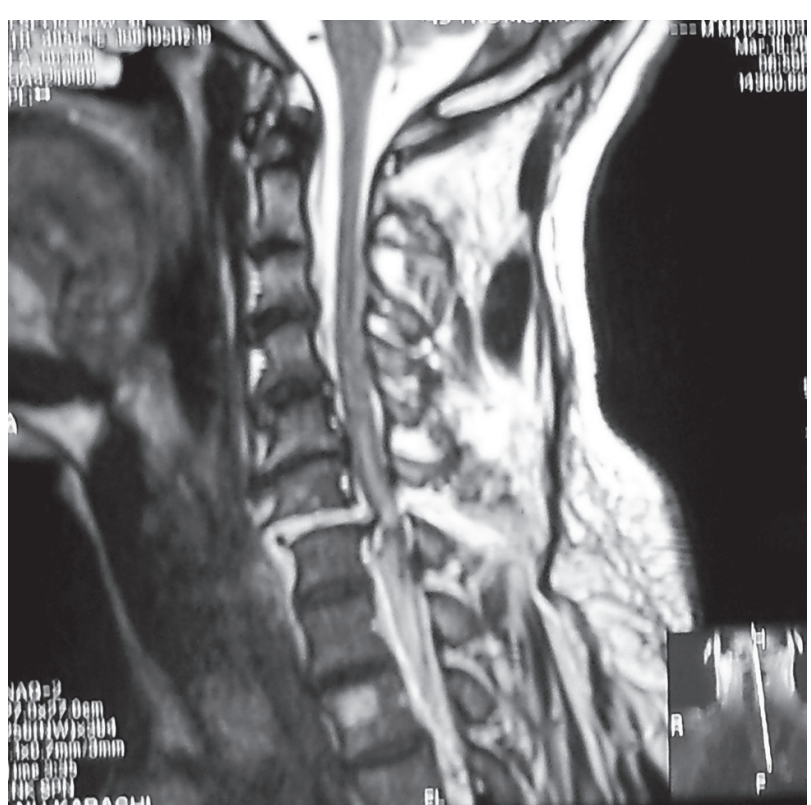

Fig. 4. Magnetic resonance imaging cervical spine T2-weighted image performed after reduction showing traumatic disc disruption at C6-7 level. A hyperintense signal is seen extending from C5 to T1 signifying cord contusion. There is also evidence of trauma to the posterior ligamentous complex.

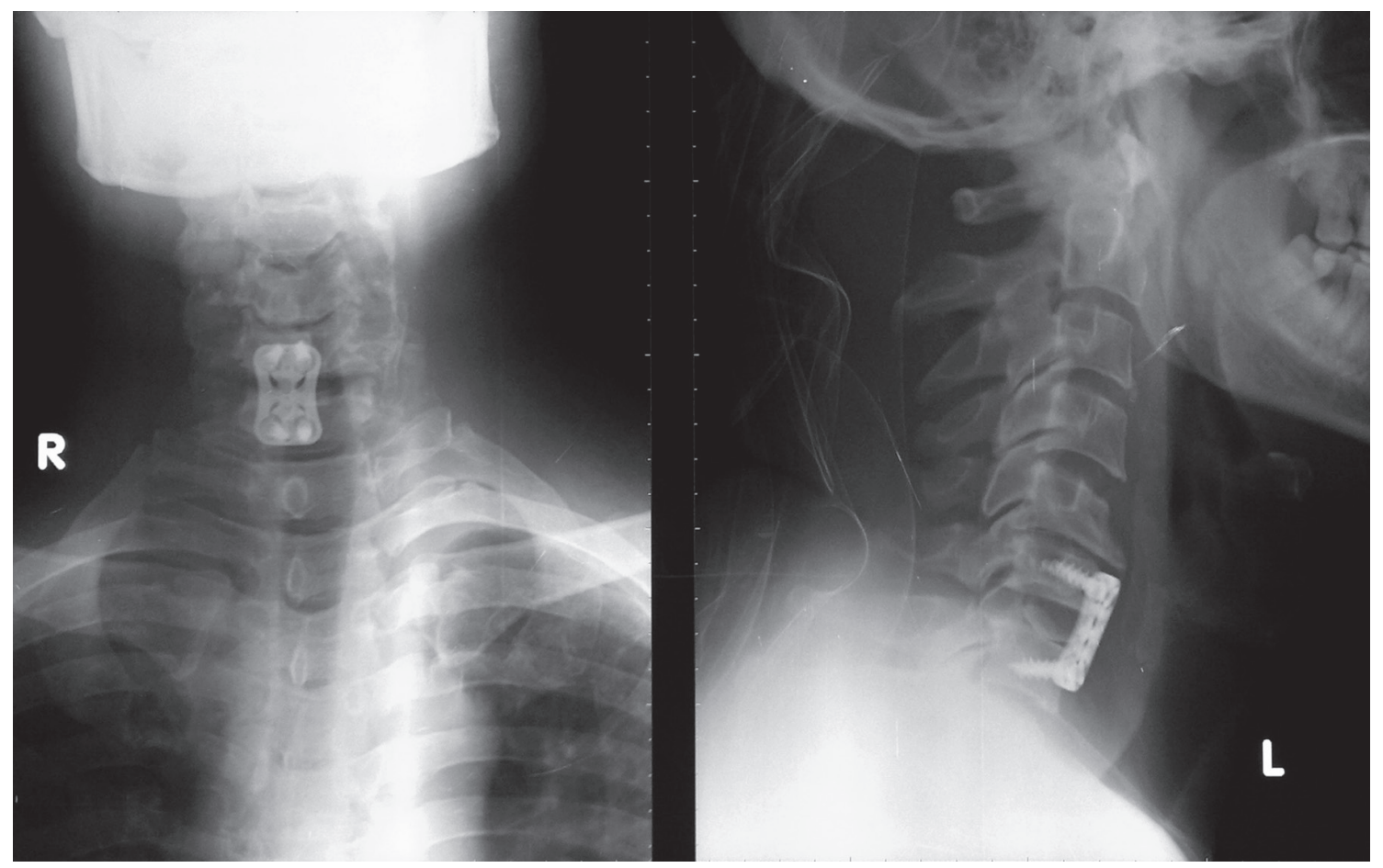

Fig. 5. Postoperative X-ray cervical spine anteroposterior and lateral views showing fusion and fixation at C6-7. 
Table 1. Demographics with pre and postoperative AIS

\begin{tabular}{|c|c|c|c|}
\hline Characteristic & Overall $(n=98)$ & Early (n=34) & Delayed $(n=64)$ \\
\hline Age (yr) & $39.2(19-65)$ & $37.5(21-65)$ & 40.1 (19-61) \\
\hline $\begin{array}{l}\text { Gender } \\
\text { Male } \\
\text { Female }\end{array}$ & $\begin{array}{l}77(78.57) \\
21(21.4)\end{array}$ & $\begin{array}{r}28(82.35) \\
6(17.64)\end{array}$ & $\begin{array}{l}49(76.56) \\
15(23.43)\end{array}$ \\
\hline $\begin{array}{l}\text { Etiology } \\
\text { RTA } \\
\text { Fall } \\
\text { Assault } \\
\text { Others }\end{array}$ & $\begin{array}{c}53(54.08) \\
22(22.44) \\
18(18.36) \\
5(5.10)\end{array}$ & $\begin{array}{c}14(41.17) \\
10(29.41) \\
8(23.52) \\
2(5.88)\end{array}$ & $\begin{array}{c}39(60.93) \\
12(18.75) \\
10(15.62) \\
3(4.68)\end{array}$ \\
\hline $\begin{array}{l}\text { AIS (preoperative) } \\
\text { A } \\
\text { B } \\
\text { C } \\
\text { D } \\
\text { E }\end{array}$ & $\begin{array}{l}36(36.73) \\
12(12.24) \\
24(24.48) \\
26(26.53)\end{array}$ & $\begin{array}{r}13(38.23) \\
4(11.76) \\
10(29.41) \\
7(20.58)\end{array}$ & $\begin{array}{r}23(35.93) \\
8(12.50) \\
14(21.87) \\
19(29.68)\end{array}$ \\
\hline $\begin{array}{l}\text { AIS (follow-up) } \\
\text { A } \\
\text { B } \\
\text { C } \\
\text { D } \\
\text { E }\end{array}$ & $\begin{array}{c}20(20.40) \\
9(9.18) \\
12(12.24) \\
32(33.67) \\
14(14.28)\end{array}$ & $\begin{array}{l}6 \text { (17.64) } \\
4(11.76) \\
5(14.70) \\
8(23.52) \\
7(20.58)\end{array}$ & $\begin{array}{c}14(21.87) \\
5(7.81) \\
7(10.93) \\
24(37.50) \\
7(10.93)\end{array}$ \\
\hline Expiry & $5(5.10)$ & $1(2.94)$ & $4(6.25)$ \\
\hline Lost to follow-up & $6(6.10)$ & $3(8.80)$ & $3(4.70)$ \\
\hline
\end{tabular}

Values are presented as number (range or \%).

AIS, American Spinal Injury Association (ASIA) Impairment Scale; RTA, road traffic accidents.

Odds ratio was used to compare the outcomes of the two groups. The data was analysed using SPSS ver. 19 (SPSS Inc., Chicago, IL, USA).

\section{Results}

Over the 5-year period, 98 patients were included in the study. They were divided in two groups according to the time of the surgical intervention: an early $(n=34)$ group and late $(\mathrm{n}=64)$ group. The mean age of the patients was 39.2 years (range, $19-65$ years), with 77 males $(78.57 \%)$ and 21 females (21.4\%). Overall, road traffic accidents were the commonest cause of injury with 53 patients (54.08\%) in this category, followed by fall and assault. The AIS at presentation was grade A in 36 (36.73\%), grade B in 12 (12.24\%), grade C in $24(24.48 \%)$ and grade D in 26 (26.53\%). There was no significant difference between the demographics $(p=0.610)$, cause of injury $(p=0.281)$ and AIS at presentation ( $p=0.755)$ between the two groups (Table 1).
An improvement of at least 1 AIS grade was seen in 18 patients (52.94\%) in the early group while it was seen in 25 patients (39.06\%) in the late group (odds ratio, 3.12; 95\% confidence interval, 1.21-8.02). Furthermore, AIS grade improvement of $\geq 2$ grades was seen in 7 patients $(23.3 \%)$ in the early group and 5 patients $(8.7 \%)$ in the late group (odds ratio, 3.05; 95\% confidence interval, 0.89-10.51). However, a maximum improvement of 3 AIS grades was seen in both the groups (Tables 2, 3). A patient in the early group was found to have deteriorated from grade $\mathrm{C}$ to $\mathrm{B}$ at the 6-month follow-up. The overall mortality in the study was $5.1 \%(n=5)$, with 1 death $(2.9 \%)$ in the early group and 4 deaths (6.2\%) in the late group. A total of 6 patients (6.1\%) were lost to follow-up during the study.

\section{Discussion}

Acute traumatic SCI is a combination of a primary and secondary injury. The primary injury which is irrevers- 
Table 2. Early surgical intervention

\begin{tabular}{|c|c|c|c|c|c|c|c|c|}
\hline $\begin{array}{l}\text { Initial } \\
\text { AIS }\end{array}$ & $\begin{array}{l}\text { Patients at } \\
\text { presentation }\end{array}$ & A & B & C & D & E & Expiry & $p$-value \\
\hline A & 13 (38.23) & $6(46.15)$ & $2(15.38)$ & $2(15.38)$ & $1(7.69)$ & None & $1(7.69)$ & $<0.01$ \\
\hline B & $4(11.76)$ & None & $1(25.0)$ & $1(25.00)$ & $1(25.00)$ & None & None & \\
\hline C & $10(29.41)$ & None & $1(10.00)$ & $2(29.00)$ & $4(40.00)$ & $3(30.00)$ & None & \\
\hline D & 7 (20.58) & None & None & None & $2(28.57)$ & $4(57.14)$ & None & \\
\hline E & Excluded from study & & & & & & & \\
\hline Total & 34 & $6(17.64)$ & $4(11.76)$ & $5(14.70)$ & $8(23.52)$ & $7(20.58)$ & $1(2.94)$ & \\
\hline
\end{tabular}

Values are presented as number (\%).

Three patients lost to follow-up.

AIS, American Spinal Injury Association (ASIA) Impairment Scale.

Table 3. Late surgical intervention

\begin{tabular}{|c|c|c|c|c|c|c|c|c|}
\hline $\begin{array}{l}\text { Initial } \\
\text { AIS }\end{array}$ & $\begin{array}{c}\text { Patients at } \\
\text { presentation }\end{array}$ & A & $\mathrm{B}$ & C & $\mathrm{D}$ & $\mathrm{E}$ & Expiry & $p$-value \\
\hline A & $23(35.93)$ & $14(60.86)$ & 2 (8.69) & $1(4.34)$ & $1(4.34)$ & None & 2 (8.69) & $<0.01$ \\
\hline B & $8(12.50)$ & None & $3(37.50)$ & $3(37.50)$ & $1(12.50)$ & None & $1(12.50)$ & \\
\hline C & $14(21.87)$ & None & None & $3(21.42)$ & $8(57.14)$ & $2(14.28)$ & $1(7.14)$ & \\
\hline D & $19(29.68)$ & None & None & None & $14(73.68)$ & $5(26.31)$ & None & \\
\hline E & Excluded from study & & & & & & & \\
\hline Total & 64 & $14(21.87)$ & $3(4.68)$ & $7(10.93)$ & $25(39.06)$ & $8(12.50)$ & $4(6.25)$ & \\
\hline
\end{tabular}

Values are presented as number (\%).

Three patients lost to follow up.

AIS, American Spinal Injury Association (ASIA) Impairment Scale.

ible results from the initial mechanical injury. It is mostly caused by a burst fracture or fracture-dislocation, acceleration-deceleration with shearing, spinal cord distraction or laceration from a penetrating injury. The secondary injury, which is preventable and reversible, is triggered by the primary injury. It is a combination of vascular changes, electrolyte imbalance, neurotransmitter accumulation, excito-toxicity, production of free radicals, inflammation and apoptosis [9-11]. It may also result from persistent compression of the spinal cord [11-13].

A better understanding of the pathophysiology of SCI has led to the introduction of novel neuro-protective therapies that alter the secondary cascade of injury. These include erythropoietin, nonsteroidal anti-inflammatory drugs, anti-CD 11d antibodies, rho antagonists, minocycline, progesterone, oestrogen, magnesium, riluzole, polyethylene glycol, atorvastatin, inosine and pioglitazone $[11,14]$. These agents modify the inhibitory SCI cascade, thus promoting axonal growth. However, most of these are still in the phase of preclinicall or clinical trials. One of these drugs is methylprednisolone, which was studied during the NASCIS trials. However, it failed to demonstrate any significant effect as compared to placebo, leading to its being used mostly based on faith [15]. In another large randomized, multicentre, double-blinded clinical trial, "The Sygen," a GM-1 ganglioside, was compared with placebo in two different doses [16].

Cervical traction had been considered for spontaneous neurological improvement in subjects undergoing conservative management $[17,18]$. However, it has an estimated risk of about $10 \%$ of neurological deterioration in patients with incomplete cervical SCI [19].

The surgical approach should be selected on the basis of the type of fracture, the age of the patient and the surgeon's experience. Whereas the biomechanical data suggests greater efficacy of the posterior approach, the anterior approach is usually preferred because it avoids prone positioning of a traumatized spine and allows di- 
rect decompression at the anterior site [20-22]. Raja et al. [23] concluded in a prospective study on 37 patients that cervical plating improves arthrodesis in patients with sub-axial SCI in addition to improving fusion rates and early rehabilitation.

With ethical issues limiting the execution of randomized controlled trials, the timing of surgical intervention remains controversial. This debate is extended to the definitions of early and delayed surgery. Early surgery has been defined as being as early as 8 hours after the injury up to 4 days after SCI. However, most of the studies have defined a 24-hour limit for early surgery [8].

Levi et al. [24] in 1991 conducted a study on 103 patients with incomplete SCI (group A, 50 patients) and complete SCI (group B, 53 patients), undergoing early ( $<24$ hours) or delayed surgery. A total of 45 patents (group A, 10; group B, 35) underwent early decompressive surgery while 58 (group $A, 40$; group $B, 18$ ) underwent delayed surgery. At discharge, 14 patients $(34.1 \%)$ from group A (5 [50\%] in the early group; 9 [22.5\%] in the delayed group) and 5 patients (9.4\%) from group B (4 [11.4\%] in the early group; 1 [5.6\%] in the delayed group) showed functional grade improvement. In 1997, Vaccaro et al. [17] performed surgical decompression on 72 patients (early, 34; late, 38) and concluded that there was no significant difference in the neurological outcome or hospital stay of patients operated on within 72 hours or after 5 days of the injury.

Papadopoulos et al. [25] in 2002 studied 91 patients with cervical SCI. Surgical decompression was performed in $34(37.3 \%)$ within 10 hours while 32 (35.1\%) underwent closed reduction within 8 hours and 25 (27.4\%) were managed conservatively. The study concluded that early surgical decompression may improve neurological recovery and reduce hospital stay. La Rosa et al. [20] conducted a systemic review in 2004 on 1,687 patients. Surgical decompression was performed in 226 patients (13.4\%) within 24 hours and in 567 patients (33.6\%) after 24 hours. The review suggested that neurological recovery is improved in patients with incomplete SCI if decompressed within 24 hours.

Chen et al. [21] published a multicentre study on the timing of surgical intervention in SCI. The patients were grouped as urgent ( $<8$ hours), early ( $8-48$ hours), and delayed ( $>48$ hours). Neurological assessment was made preoperatively, postoperatively, at 6 months postoperatively and at 1 year postoperatively. Although the final recovery in both the urgent and early groups was similar, prompt neurological improvement was observed in patients undergoing urgent surgery while patients undergoing early surgery showed gradual recovery. However, no neurological improvement along with increased morbidity was observed at 6 months and at the 1-year follow-up in patients undergoing delayed surgical intervention.

Recently, Surgical Timing in Acute Spinal Cord Injury Study (STASCIS), the largest multi-centre, international, cohort study for acute SCI, was published. The study recruited 313 patients out of which 182 patients underwent early ( $<24$ hours) decompression with a mean of $14.2 \pm 5.4$ hours until the surgery while 121 patients in the delayed group underwent decompressive surgery with a mean time of $48.3 \pm 29.3$ hours until the surgery. Methylprednisolone was used during the study as per the recommendations of the NASCIS-2 trial [22]. The study concluded that the odds of at least 2 AIS grade improvement were 2.8 times more in the early group [8]. The study, however, had a high complication rate of $32.2 \%$. The lost to followup fraction of the patients was $27 \%$ in the study.

Lukas et al. [26] performed a retrospective analysis on 34 patients undergoing surgery for SCI. Patients were grouped into 4 groups according to the injury-to-surgery interval. The Fankel scale was used for assessment of the patients at the 6-month follow-up. A significant difference was found between the patients operated on within 24 hours and after 1 week of the injury. A paired comparison between other sub-groups did not show any significant results because of the limited number of patients in each group.

A multicentre cohort study was conducted in North America using 24 hours as a cut-off margin for early and late surgery. A total of 84 patients (early, 35; late, 49) were recruited, out of which only 55 patients were available for neurological assessment at rehabilitation discharge. A significantly greater proportion of patients showed at least 2 AIS improvement in the early surgery group [27].

Our study had a single-institution, non-randomized cohort with a smaller sample size for acute SCI. The mean time to surgery was 18.4 hours (range, 13-24 hours) in the early group and 52.7 hours (range, 31-124 hours) in the late group, which is comparable to the STASCIS. The complication rate in our study was $11.2 \%$ (4 in early and 7 in delayed surgery group). One of the patients in the early group expired during surgery as a result of cardiopulmonary arrest. A total of 3 patients expired in the 
late group including 2 from pulmonary embolism. One patient in the late group developed bedsores and urinary tract infection. He later died of sepsis.

\section{Study limitations}

The study is based on a non-randomized sample. It is limited to only a single surgeon's experience. Moreover, factors that caused a delay in surgical intervention may have influenced the final outcome. This study has not analysed the impact of these factors.

\section{Conclusions}

From our knowledge of secondary injury mechanisms, it can be stated that early surgical decompression dictates a neuro-protective effect. Determining the specific time frame is difficult. Our study suggests that early decompression within 24 hours of the injury had a better neurological outcome defined as at least 2 grade AIS improvement at the 6-month follow-up. Therefore, we recommend early decompression of traumatic SCI in all cases whenever feasible.

\section{Conflict of Interest}

No potential conflict of interest relevant to this article was reported.

\section{References}

1. Wyndaele M, Wyndaele JJ. Incidence, prevalence and epidemiology of spinal cord injury: what learns a worldwide literature survey? Spinal Cord 2006;44: 523-9.

2. Korres DS. Injuries of the cervical spine. Athens: Litsas Medical Publications; 1993.

3. Fehlings MG, Sekhon L. Cellular, ionic and biomolecular mechanisms of the injury process. In: Benzel EC, Tator $\mathrm{CH}$, editors. Contemporary management of spinal cord injury: from impact to rehabilitation. Chicago: American Association of Neurologic Surgeons; 2005. p.33-50.

4. Amar AP, Levy ML. Pathogenesis and pharmacological strategies for mitigating secondary damage in acute spinal cord injury. Neurosurgery 1999;44:102739.
5. Bracken MB, Holford TR. Effects of timing of methylprednisolone or naloxone administration on recovery of segmental and long-tract neurological function in NASCIS 2. J Neurosurg 1993;79:500-7.

6. Bracken MB, Shepard MJ, Holford TR, et al. Administration of methylprednisolone for 24 or 48 hours or tirilazad mesylate for 48 hours in the treatment of acute spinal cord injury. Results of the Third National Acute Spinal Cord Injury Randomized Controlled Trial. National Acute Spinal Cord Injury Study. JAMA 1997;277:1597-604.

7. Nesathurai S. Steroids and spinal cord injury: revisiting the NASCIS 2 and NASCIS 3 trials. J Trauma 1998;45:1088-93.

8. Fehlings MG, Vaccaro A, Wilson JR, et al. Early versus delayed decompression for traumatic cervical spinal cord injury: results of the Surgical Timing in Acute Spinal Cord Injury Study (STASCIS). PLoS One 2012;7:e32037.

9. Dietrich WD, Chatzipanteli K, Vitarbo E, Wada K, Kinoshita $\mathrm{K}$. The role of inflammatory processes in the pathophysiology and treatment of brain and spinal cord trauma. Acta Neurochir Suppl 2004;89:6974.

10. Casha S, Yu WR, Fehlings MG. Oligodendroglial apoptosis occurs along degenerating axons and is associated with FAS and p75 expression following spinal cord injury in the rat. Neuroscience 2001;103: 203-18.

11. Fehlings MG, Perrin RG. The role and timing of early decompression for cervical spinal cord injury: update with a review of recent clinical evidence. Injury 2005; 36 Suppl 2:B13-26.

12. Carlson GD, Gorden CD, Oliff HS, Pillai JJ, LaManna JC. Sustained spinal cord compression: part I: timedependent effect on long-term pathophysiology. J Bone Joint Surg Am 2003;85:86-94.

13. Yoshida H, Okada Y, Maruiwa H, et al. Synaptic blockade plays a major role in the neural disturbance of experimental spinal cord compression. J Neurotrauma 2003;20:1365-76.

14. Kwon BK, Okon EB, Plunet W, et al. A systematic review of directly applied biologic therapies for acute spinal cord injury. J Neurotrauma 2011;28:1589-610.

15. Coleman WP, Benzel D, Cahill DW, et al. A critical appraisal of the reporting of the National Acute Spinal Cord Injury Studies (II and III) of methylpred- 
nisolone in acute spinal cord injury. J Spinal Disord 2000;13:185-99.

16. Geisler FH, Coleman WP, Grieco G, Poonian D; Sygen Study Group. The Sygen multicenter acute spinal cord injury study. Spine (Phila Pa 1976) 2001;26(24 Suppl):S87-98.

17. Vaccaro AR, Daugherty RJ, Sheehan TP, et al. Neurologic outcome of early versus late surgery for cervical spinal cord injury. Spine (Phila Pa 1976) 1997;22:2609-13.

18. Tator CH, Duncan EG, Edmonds VE, Lapczak LI, Andrews DF. Neurological recovery, mortality and length of stay after acute spinal cord injury associated with changes in management. Paraplegia 1995;33: 254-62.

19. Katoh S, el Masry WS, Jaffray D, et al. Neurologic outcome in conservatively treated patients with incomplete closed traumatic cervical spinal cord injuries. Spine (Phila Pa 1976) 1996;21:2345-51.

20. La Rosa G, Conti A, Cardali S, Cacciola F, Tomasello F. Does early decompression improve neurological outcome of spinal cord injured patients? Appraisal of the literature using a meta-analytical approach. Spinal Cord 2004;42:503-12.

21. Chen Q, Li F, Fang Z, et al. Timing of surgical decompression for acute traumatic cervical spinal cord injury: a multicenter study. Neurosurg Q 2012;22:61-8.

22. Bracken MB, Shepard MJ, Collins WF, et al. A randomized, controlled trial of methylprednisolone or naloxone in the treatment of acute spinal-cord injury: results of the Second National Acute Spinal Cord Injury Study. N Engl J Med 1990;322:1405-11.

23. Raja RA, Makhdoom A, Qureshi AA. Anterior decompression, fusion and plating in cervical spine injury: our early experience. J Ayub Med Coll Abbottabad 2008;20:73-6.

24. Levi L, Wolf A, Rigamonti D, Ragheb J, Mirvis S, Robinson WL. Anterior decompression in cervical spine trauma: does the timing of surgery affect the outcome? Neurosurgery 1991;29:216-22.

25. Papadopoulos SM, Selden NR, Quint DJ, Patel N, Gillespie B, Grube S. Immediate spinal cord decompression for cervical spinal cord injury: feasibility and outcome. J Trauma 2002;52:323-32.

26. Lukas R, Barsa P, Pazour J, Sram J. Timing of surgical intervention in acute spinal cord injury and postoperative neurological recovery. Acta Chir Orthop Traumatol Cech 2012;79:233-7.

27. Wilson JR, Singh A, Craven C, et al. Early versus late surgery for traumatic spinal cord injury: the results of a prospective Canadian cohort study. Spinal Cord 2012;50:840-3. 